\title{
Outcome of severe traumatic brain injury at a critical care unit: a review of 87 patients
}

\begin{abstract}
E.A. Opondo, MBChB, MMed (Surg), General surgeon, North Kinangop Mission Hospital, Surgery Department and The Mater Hospital Nairobi, surgery department, N.J.M. Mwangombe, MBChb, MMed(surg), PhD (Lond), Associate Professor, Department of Surgery, University of Nairobi and Head Division of Neurosurgery
\end{abstract}

Corresponding author:

Dr. E.A. Opondo, P.O. Box 00202105, Nairobi, Email dropondo@yahoo.co.uk

\section{Abstract}

OBJECTIVE: To determine the outcome of severe traumatic brain injury and to document the factors influencing mortality.

DESIGN: A six months prospective study.

SETTINGS: The intensive care unit (ICU) of Kenyatta National Hospital (KNH), a tertiary referral centre in Kenya.

SUBJECTS: Eighty Seven adult patients with severe traumatic brain injury admitted between April and September 2005.

METHODS: Basic demographic, clinical, radiological and mechanism of injury data were recorded at admission and during ICU stay. The main outcome measure was survival or death. The outcome groups were compared for the injury severity, mean arterial pressure, serum glucose level, grade of diffuse axonal injury and the presence of mydriasis and anisocoria using the $\mathrm{X}^{2}$ test and the Fischers Exact test as appropriate.

RESULTS: Severe traumatic brain injury accounted for $14.3 \%$ of all ICU admissions. This study included 73 men (83.9\%) and 14 women $(16.1 \%)$ with a mean patient age of 34 \pm 17 years. Motor vehicle accidents were the main cause $(58.6 \%)$. Forty six patients $(54.0 \%)$ died. Twenty nine percent of patients had persistent vegetative state or severe disability. Factors that were associated with poor outcome on univariate analysis were Glasgow coma scale of less than 5, diffuse axonal injury and intracerebral mass lesions and blood sugar greater than $10 \mathrm{mmol} / \mathrm{L}$.

CONCLUSION: Severe TBI is a frequent cause of hospital admission to critical care units among young men with a high mortality (54\%) rate.

\section{Introduction}

Traumatic brain injury (TBI) has been termed a "silent global epidemic", accounting forup to $30 \%$ of all trauma related deaths and is the leading cause of death in young males in developed countries $(1,2)$. It is considered to be a dual insult comprising primary and secondary processes. The primary injury is the physical or anatomic damage caused at the time of injury producing vulnerable cells that are further compromised by secondary brain injury factors (3-6). The factors commonly associated with secondary insults include hypotension, hypothermia, hypoxia, acidosis 
and raised intracranial pressure $(1,3,5)$. When these are present, mortality rises to $35-36 \%(1,5)$ as documented in the Traumatic coma Data Bank study (1884-1987) and that by Jeremitsky et al. In an earlier study at the Kenyatta National Hospital $(\mathrm{KNH})$, patients with a pulse rate of less than 60 per minute at the time of admission had a mortality of $100 \%$ while $69 \%$ of those with pulse rate greater than 120 per minute had poor outcome (7). In managing severe TBI therefore, avoiding secondary brain injury is key.

The accurate prediction of short term and long term outcomes is useful for communication with the patient's family and health care professionals. Of the commonly used outcome measures, the Glasgow outcome scale is the oldest. It consists of five categories namely death, persistent negative state, severe disability, moderate disability and good recovery. The current study aimed to evaluate the outcome and predictors of outcome of severe traumatic brain injury at ICU of Kenyatta National Hospital.

\section{Materials and methods}

Patients: This prospective study included all the consecutive adult patients with severe traumatic brain injury admitted to the ICU of Kenyatta National Hospital between April and September 2005.They were examined by the first author and scored according to Glasgow coma scale (GCS) on arrival. They then underwent computed tomography (CT scan) as soon as this was practical. The study excluded patients with GCS of greater than 8 as those were admitted to the general wards. Patients meeting the study criteria were resuscitated according to advanced trauma life support (ATLS) protocols with supervision of the attending surgeon. Further data was collected on the cause of TBI, age, gender, vital signs and pupillary responses. Anisocoria was defined as pupillary inequality of more than $1 \mathrm{~mm}$ and mydriasis as fixed and dilated pupils of $4 \mathrm{~mm}$ or more in diameter. Hypotension was defined as mean arterial pressure of less than $70 \mathrm{mmHg}$. The biochemical parameters measured at admission and during ICU stay included arterial blood gases, acid-base state, serum glucose and electrolytes.
Outcome data included hospital complications, mortality, status at discharge from ICU and length of ICU/hospital stay recorded. The CT scans were reported by one radiologist in collaboration with the investigators and classified according to Marshal's classification. In this classification, the status of the mesencephalic cisterns, the degree of midline shift in millimeters, and the presence or absence of one or more surgical masses are considered. Diffuse Injury I included all head injuries where there was no visible pathology; Diffuse Injury II included all injuries in which the cisterns were present, the midline shift was less than $5 \mathrm{~mm}$, and/or there was no high- or mixeddensity lesion of more than $25 \mathrm{cc}$; Diffuse Injury III included injuries with swelling where the cisterns were compressed or absent and the midline shift was 0 to $5 \mathrm{~mm}$ with no high- or mixed-density lesion of more than 25 cc; and Diffuse Injury IV included injuries with a midline shift of more than $5 \mathrm{~mm}$ and with no high- or mixed-density lesion of more than $25 \mathrm{cc}$ The outcome status was based on the Glasgow Outcome Score which ranged from good recovery to death in five categories. Good recovery was defined as capacity to resume normal occupational activities, while with moderate disability the patient was independent and resumed only part of activities of daily living. In case of severe disability the patient was not able to engage in most previous personal, social and work activities unless with some form of assistance, while in persistent vegetative state the patient was not aware of surroundings or only partially responded to stimuli. Poor outcome in this study was defined as death, persistent vegetative state or severe disability.

Statistical analysis: Analysis of the data was carried out using SPSS version 12 program to derive descriptive statistics and frequency distributions. Categorical data were expressed in terms of proportions while continuous variables were expressed as means and standard deviations.

Subgroups (survival \& death) were analyzed in a univariate way using student t-test, chi square test and Ficher exact tests as appropriate. Significance was set at $p$ less than 0.05 . 


\section{Results}

Patient and injury characteristics: Eighty seven patients were reviewed. This represented 14.3\% of the 609 adult ICU admissions. There were 73 men $(83.9 \%)$ and 14 women $(16.1 \%)$ with a mean age of $34 \pm 17$ years. The demographic and clinical parameters at admission are shown in Table 1.

Majority of the patients were aged 25-39 years $(50.6 \%)$, while $21 \%$ were $40-60$ years. Five percent of the patients were aged over 60 years.
Trauma in majority of the patients was due to motor vehicle accidents (58.6\%) followed by assaults in $32.2 \%$. Three patients (3.4\%) were received in coma having been found on the streets by policemen with no clear history about their injuries being availed (Table 2).

Extracranial pathology was present in 78 patients (91.6\%). Maxillofacial injury was present in 53 patients $(49.5 \%)$ and limb fractures were seen in 27 patients $(25.2 \%)$. Twenty of the patients with limb fractures had operative fixation and the rest were managed conservatively. Ten patients had a combination

Table 1: Demographic and Clinical Parameters at admission

\begin{tabular}{lrc}
\hline Parameter & Results & (\%) \\
\hline Mean Age \pm SD (Years) & $34 \pm 17$ & - \\
Sex (M/F) & $73 / 14$ & - \\
Mean \pm SD Glasgow coma scale score & $4.95 \pm 3$ & 36.8 \\
Anisocoria & 32 & \\
Bilateral mydriasis & 21.4 & 15 \\
Rhinorhoea & 15 & 10.3 \\
Otorrhoea & 9 & - \\
Mean arterial pressure (mmHg) & $101 \pm 31.6$ & - \\
Glucose level (mmol/l) & $8.9 \pm 4.4$ & - \\
Potassium level (mmol/l) & $3.9 \pm 3.85$ & \\
Sodium level (mmol/l) & $137 \pm 10$ & \\
\hline
\end{tabular}

Table 2: Mechanism of injury

\begin{tabular}{lcc}
\hline Mechanism & Frequency & Percentage \\
\hline Motor vehicle injury & 51 & 58.6 \\
Fall from height & 2 & 2.3 \\
Assault & 28 & 32.2 \\
Fall of object & 1 & 1.1 \\
Firearm/missile & 2 & 2.3 \\
Unknown & 3 & 3.4 \\
\hline Total & 87 & 100.0 \\
\hline
\end{tabular}


of limb fractures and maxillofacial injury while five patients had maxillofacial injury, chest trauma, and limb injury combined. Four patients presented with abdominal injuries (2 with splenic ruptures).

Fifty two patients (59.8\%) were seen at the casualty within 1-4 hours of injury while $4.5 \%$ presented between 4 and 24 hours after injury. The rest arrived within an hour. On admission 43 patients $(49.4 \%)$ had GCS of $3-5$ and 44 patients $(50.6 \%)$ had GCS of 5-8.

Fifteen patients with intracranial haematomas or mass lesions underwent craniotomy, burr holes and elevation of skull fractures based on the assessment of a neurosurgeon.

Outcome evaluation: Forty five patients died on the initial ICU admission while one with severe disability died on readmission to ICU from the wards (total mortality of 54\%). On discharge from ICU, $19(21.8 \%)$ patients had persistent vegetative state, $7(8.0 \%)$ severe disability, $7(8.0 \%)$ moderate disability and $9(10.3 \%)$ had good recovery.

Anumber of patients and clinical parameters were related to outcome. Poor outcome in the age group 25-39 was 52.3\%, 40-60 years $(23.1 \%), 15-24$ years $(16.9 \%)$ and for those over 60 years $(7.7 \%)$. Both the patients with splenic ruptures were admitted in hypovolemic shock, operated on, and died. Glasgow coma scores of 3-5 correlated with a high mortality $(76.7 \%)$ as shown in Table 3 and Figure 1. Seventy five patients had blood sugar levels taken of which $50(66.7 \%)$ patients had levels less than $10 \mathrm{mmol} / \mathrm{L}$ while 25 (33.3\%) patients had levels more than $10 \mathrm{mmol} / \mathrm{L}$. Eighty eight percent of the patients with blood glucose levels of more than 10mmol/L died ( $\mathrm{P}=0.010)$ (Table 3).

Hypotension was recorded among 16 patients $(23 \%)$ on admission. The rest had normal pressure. Of the 71 patients who had head CT scanning done, 58 patients $(81.7 \%)$ had diffuse axonal injury III/IV and mass lesions while 13 patients $(18.3 \%)$ had diffuse axonal injury grade I/II. Mortality in axonal injury grade I/II and III/IV was $30 \%$ and $64 \%$ respectively.

Anisocoria was present in 27 patients while rhinorrhoea was present in 15 patients and ortorrhoea in 9 patients. Five patients had both ortorrhoea and Rhinorrhoea and all died.

Table 3 summarizes the group comparisons.

Figure 1: Mortality based on GCS Value

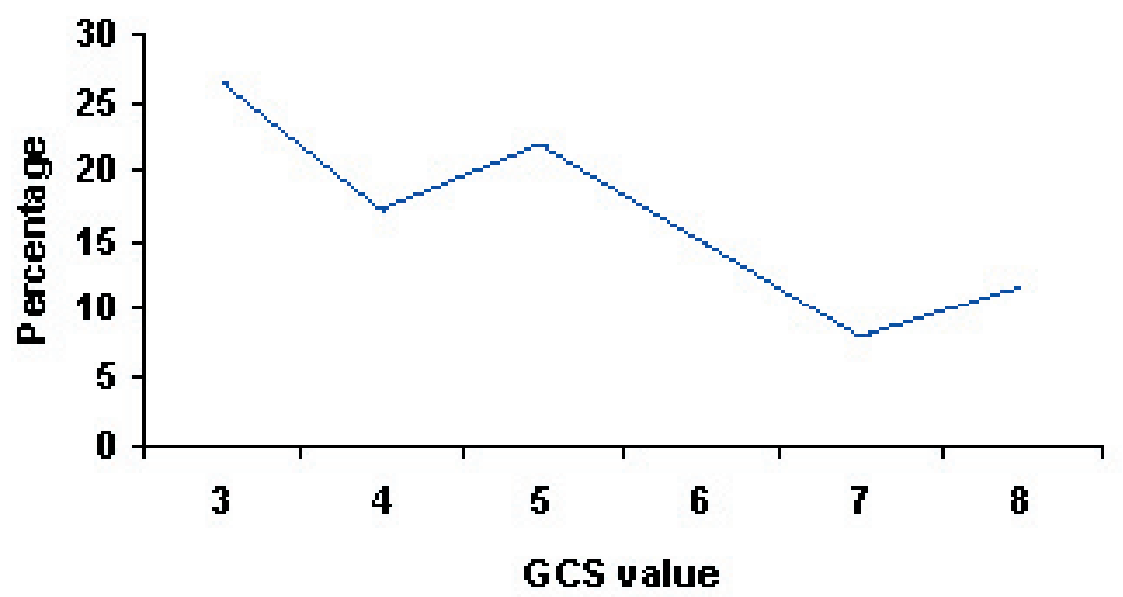


Table 3: Composite table of the clinical, laboratory and demographic data analyzed.

\begin{tabular}{|c|c|c|c|c|}
\hline \multicolumn{2}{|c|}{ Variable } & \multirow{2}{*}{$\begin{array}{c}\text { Survival }(n=41) \\
10 \\
31\end{array}$} & \multirow{2}{*}{$\begin{array}{c}\text { Mortality }(n=46) \\
33 \\
13\end{array}$} & \multirow{2}{*}{$\begin{array}{r}\text { P-value } \\
0.034\end{array}$} \\
\hline GCS & $\begin{array}{l}3-5 \\
5-8\end{array}$ & & & \\
\hline Blood & $\begin{array}{l}\text { ugar } \\
<10 \mathrm{mmol} / \mathrm{l} \\
>10 \mathrm{mmol} / \mathrm{l}\end{array}$ & $\begin{array}{l}25 \\
3\end{array}$ & $\begin{array}{l}25 \\
22\end{array}$ & 0.010 \\
\hline MAP & $\begin{array}{l}<70 \mathrm{mmhg} \\
>70 \mathrm{mmhg}\end{array}$ & $\begin{array}{c}4 \\
26\end{array}$ & $\begin{array}{l}12 \\
26\end{array}$ & 0.069 \\
\hline Aniso & $\begin{array}{l}\text { Pria } \\
\text { Present } \\
\text { Absent }\end{array}$ & $\begin{array}{c}9 \\
24\end{array}$ & $\begin{array}{l}18 \\
28\end{array}$ & 0.197 \\
\hline Mydri & $\begin{array}{l}\text { Present } \\
\text { Absent }\end{array}$ & $\begin{array}{c}5 \\
28\end{array}$ & $\begin{array}{l}15 \\
31\end{array}$ & 0.065 \\
\hline Rhino & $\begin{array}{l}\text { oea } \\
\text { Present } \\
\text { Absent }\end{array}$ & $\begin{array}{c}8 \\
25\end{array}$ & $\begin{array}{c}7 \\
39\end{array}$ & 0.235 \\
\hline Diffus & $\begin{array}{l}\text { axonal injury } \\
\text { I/II } \\
\text { III/IV }\end{array}$ & $\begin{array}{l}10 \\
21\end{array}$ & $\begin{array}{c}3 \\
37\end{array}$ & 0.009 \\
\hline
\end{tabular}

\section{Discussion}

The results of the current study indicate a very high morbidity associated with intensive care of severe TBI at KNH. This occurs in a cohort of very young patients. Extracranial injuries were recorded in $91.6 \%$ of victims with the face and limbs being the commonest. The mean age of $34 \pm 17$ years with $70.1 \%$ of these patients aged 18 to 39 years has profound economic implications. Injury robs these individuals in active employment their daily earnings and invites relatives to pay high ICU and hospital bills. Severe TBI patients represented $14.3 \%$ of the ICU admissions during the six months study period and of this only $44 \%$ survived. Our result on patient age concur with previous studies (79). Jeremitsky and colleagues have reported a mean age of 34 years (5). The mortality rate of $54 \%$ in the current study is however much higher than in previous reports $(1,5,10,11)$. The reported rate was $36 \%$ in the study by Jeremitsky et al (5) and $35 \%$ in the traumatic coma data bank study (1). The high mortality in this study could be explained by high frequency of multiple injuries and late presentation to hospital. Most patients in this study presented one to four hours after the injury with subsequent delays in starting definitive management. The rate and pattern of extracranial injuries (91.6\%) in this study could likely be explained by the mechanism of injury. Motor vehicle accidents and mob justice accounted for $90.8 \%$ of the injuries.

In the current study a GCS of 3-5 was associated with poor outcome. The GCS scoring system, first described by Teadale and Janet (12) to quantify the state of consciousness, correlates well with neurological outcome (1214). Quigley et al.(15) retrospectively reviewed all the patients admitted to their trauma center over three years who had GCS of 3, 4 and 5, and found their overall survival to be low (12.5\%). Combined with pupillary abnormalities and old age, survival was even lower (15). In the prospective study by Ritter et al(16), GCS score $<8$ was associated with death or vegetative state in $39 \%$ of patients with two reactive pupils but $85 \%$ of those with both pupil non reactive. In the current study the results on anisocoria and mydriasis were not significant. Pupillary reactivity is correlated with cerebral blood flow. In the study by Ritter et al. patients with the bilateral mydriasis had cerebral blood flow 
of $30.5 \pm 16.8 \mathrm{ml} / 100 \mathrm{~g} /$ minute compared to $43.8 \pm 10.7 \mathrm{ml} / 100 \mathrm{~g} /$ minute in those with normal reactivity.

There is a direct relationship between the four diagnostic categories of diffuse axonal injury on CT scan and the mortality rate (17). Patients suffering diffuse injury with no visible pathology (Diffuse Injury I) have the lowest mortality rate $(10 \%)$, while the mortality rate in patients suffering diffuse injury with a midline shift (Diffuse Injury IV) is greater than $50 \%(17,18)$. When used in conjunction with the traditional division of intracranial hemorrhages (extradural, subdural, or intracerebral), this categorization allows a much better assessment of the risk of intracranial hypertension and of a fatal or nonfatal outcome (18). Unfortunately intracranial pressure measurements are not routinely done at $\mathrm{KNH}$ and therefore it was not possible to assess the impact of the various intracranial hemorrhages with associated diffuse axonal injury on outcome. In the current study the mortality rate was $30 \%$ and $64 \%$ in patients with diffuse axonal injury I/II and III/ IV respectively.

The negative influence of secondary systematic insults (SSI) in severe TBI is now well documented (5-9). The SSI are now divided into subgroups of respiratory SSI (hypoxemia, hypercapnia, hypocapnia), Circulatory SSI (arterial hypotension and hypertension) and metabolic or electrolyte SSI (anemia, hyper or hypoglycemia hyponatraemia, hypo or hyperkalemia). In the current study, serum glucose levels higher than $10 \mathrm{mmol} / 1$ correlated with poor outcome on analysis $(\mathrm{P}=0.010)$ which is consistent with other studies $(5,6)$. Jeremitsky et al (5) found hyperglycemia in $40 \%$ of patients with severe TBI and this was associated with increased mortality and longer hospital stay. In neurotrauma high serum glucose is thought to exacerbate secondary brain injury. Probably hyperosmolality, lactic acid production, alterations in neuronal $\mathrm{PH}$ and increases in excitatory amino acids lead to neuronal injury.

Hypotension has been incriminated more than any other SSI in the worsening TBI. A multicenter study using information from traumatic coma Data Bank illustrated that blood pressure less than $80 \mathrm{mmh}$ worsened outcome at 6 months based on Glasgow outcome scale(8). It has specifically been shown that hypotension occurring in the prehospital phase, at admission or in ICU significantly increases mortality and poor outcome (10). Chestnut showed that the combination of hypotension and hypoxia resulted in a $75 \%$ mortality rate (19). In this study 16 patients $(23 \%)$ had hypotension as evidenced by mean arterial pressure below $70 \mathrm{mmhg}$. The hypotensive patients had longer ICU stay with a $75 \%$ mortality recorded in this group.

There is a great deal of research into the biochemical and pathophysiological processes at work locally within the injured brain, but the fact remains that current monitoring and intervention is based on systemic or global brain variables. Moreover, there may also be a burden of undetected or unreported systemic hypoxiaand or hypotension before admission to hospital. Although our data may only confirm earlier research findings and the opinion of most clinicians that low GCS and secondary brain injury are signs of poor prognosis, it is also inevitable that as monitoring equipment develops, ever greater quantities of this kind of data will be generated.

\section{Conclusion}

Severe traumatic brain injury is a frequent cause of ICU admission especially among young patients and is associated with high mortality and morbidity. The outcome of severe TBI is poor and this is influenced by demographic, clinical, and CT Scan findings. Glasgow coma scale lower than 5, diffuse axonal injury IV and intracranial mass lesions and blood glucose higher than $10 \mathrm{mmol} / 1$ correlated with poor outcome on univariate analysis in this study.

\section{Acknowledgements}

To the Director, Kenyatta National Hospital, for granting permission to publish these findings and to the Standards and Ethics Committee,Kenyatta National Hospital, for permission to carry out the study. 


\section{References}

1. Marshall L.F., Marshal S.B., Klaubler M.R., et al. Report on the traumatic coma data bank: The outcome of severe closed head injury: J. Neurosurg. 1991; 75: 528-536.

2. MillerJ.D.Head injury and brain ischaemia implications for therapy. Brit. J. Anaesth. 1985; 57: 120-129.

3. Sarrafzadeh A.S., Petonen E.E., Kaisers U., et al. Secondary insults in severe head injury. Crit. Care Med. 2001; 29: 1116-1123.

4. Marmarou A., Anderson R.L., Ward J.D., et al. Impact of ICP instability and hypotension on outcome in patients with severe head injury trauma. J. Neurosurg. Anaesth. 1991; 75: 559-566.

5. Jeremitsky E., Omest L., Laurel A., Dunhan C.M., et al. Harbingers of poor outcome the day after severe brain injury. J. Trauma. 2003; 54: 312-319.

6. Jones P.A., Andrews P.J., Midgleys S., et al. Measuring the burden of secondary insults in headinjured patients during intensive care. J. Neurosurg. Anaesthesiol. 1994; 6: 4-8.

7. Mwangombe N.J.M. and Kiboi J. Factors influencing outcome of severe head injury at Kenyatta National Hospital: East Afr. Med. J. 2001; 78: 238-241.

8. The Brain Trauma Foundation. The American Association of Neurological Surgeons. The Joint Section on Neurotrauma and Critical Care. Initial management. J. Neurotrauma. 2000; 17: 463-70.

9. The Brain Trauma Foundation. The American Association of Neurological Surgeons. The Joint Section on Neurotrauma and Critical Care. Hypertension. J. Neurotrauma. 2000; 17: 591.

10. Wald S., Fenwik J. and Shackford S.R. The effect of secondary insults on mortality and long-term disability of severe head injury in a rural region without a trauma system. J. Trauma. 1991; 31: 104-110

11. Ruwaid Isa M.B., Wan A., Ghazaime G., et al. Outcome of severe head traumatic brain injury: Compassion of 3 monitoring approaches. J. Neurol. Neurosurg. 2004; 6: $2-5$.

12. Teasdale G., Jennett B., Braakman R., et al. Assessment of coma and impaired consciousness. A practical scale. Lancet. 1974; 2: 81-84.

13. Fischer J. and Mathieson C. The history of the Glasgow Coma Scale; Implications for practice. Crit. Care Nurs. 2001; 23: 52-58.

14. Norwood S., McAuley C., Berne J., et al. A prehospital Glasgow Coma scale score <or - 14 accurately predicts the need for full trauma team activation and patient hospitalization after motor vehicle collision. J. Trauma. 2002; 53: 503-507.

15. Quigley M.R., Vidovich D., Cantella D., et al. Determining the rate of survivorship after very severe injury. Arch. Surg. 2002; 137: 285-290

16. Ritter A.M., Muizelaar J.P., Barnes T., et al. Brain stem blood flow, pupillary response, and outcome in patients with severe head injuries. Neurosurg. 1999; 44: 941-948.

17. Marshall L.F., Klauber M.R., Marshall S.B., et al. The diagnosis of head injury requires a classification based on computerized axial tomography. J. Neurotrauma. 1992; 9(supp 1): s287-s282.

18. The Brain Trauma Foundation. The American Association of Neurosurgical Surgeons. The joint section on neurotrauma and critical care. Computed tomography features. J. Neurotrauma. 2000; 17: 579-627.

19. Chesnut R.M. Avoidance of hypotension: conditio sie qua non of successful severe head injury management. J. Trauma. 1997; 42: 54-59. 